\section{Evaluation of Multipass Mechanical Harvesting on 'Skeena' Sweet Cherries Trained to Y-trellis}

\author{
Long He \\ The Center for Precision and Automated Agricultural Systems, Washington \\ State University, Prosser, WA
}

Jianfeng Zhou

The Center for Precision and Automated Agricultural Systems and Department of Biological Systems Engineering, Washington State University, Pullman, WA

Qin Zhang

The Center for Precision and Automated Agricultural Systems, Washington State University, Prosser, WA

\author{
Manoj Karkee ${ }^{1}$ \\ The Center for Precision and Automated Agricultural Systems and Department \\ of Biological Systems Engineering, Washington State University, Prosser, WA
}

Additional index words. sweet cherries, mechanical harvesting, single-pass harvesting, multipass harvesting, fruit removal rate, fruit damage rate

\begin{abstract}
A study on multipass harvesting using a mechanical harvesting prototype was proposed for mechanical harvesting of fresh market sweet cherries. Fruit damage rate, fruit removal rate, and fruit maturity level were three of the measures used to compare the performance of the multipass harvesting method against single-pass harvesting. The multipass harvesting was conducted in four consecutive days with short duration of 2.5 seconds at each day, while the single-pass harvesting was one-time harvesting with long duration of 10 seconds at a single day. To generate baseline information for comparison, single-pass harvestings were performed on the first and the last days of the multipass harvesting. Fruit maturity level was determined by comparing the fruit skin color against a standard color chart with seven color levels. Field test results showed that the percentage of under-mature fruit (maturity levels $\leq 5$ ) was substantially lower with multipass harvesting than that with day 1 single-pass harvesting. Similarly, the percentage of over-mature fruit (maturity level 7) was noticeably lower with multipass harvesting than that with day 4 single-pass harvesting. Multipass harvesting achieved a fruit removal rate of $83.4 \% \pm 10.3 \%$ and a harvest-induced fruit damage rate of $5.0 \% \pm$ 4.4\%. The corresponding fruit removal rates from single-pass harvesting tests were $48.0 \% \pm 16.1 \%$ on day 1 and $66.7 \% \pm 16.2 \%$ day 4 . Harvest-induced fruit damage rates with single-pass harvesting were $20.1 \% \pm 9.9 \%$ on day 1 and $11.8 \% \pm 6.0 \%$ on day 4 . The results supported the hypothesis that multipass of short-duration shaking offer a potential to achieve a higher overall harvesting efficiency with better fruit quality, and therefore could lead to an optimal solution for mechanical harvesting of fresh market sweet cherries. It is noted that comprehensive economic analysis will be necessary to establish commercial viability of the system in comparison with single-pass solutions.
\end{abstract}

Received for publication 30 Jan. 2015. Accepted for publication 6 July 2015.

This research was supported in part by Washington State University Agricultural Research Center federal formula funds (Project No. WNP0745 and WNP0728) received from the U.S. Department of Agriculture National Institutes for Food and Agriculture (NIFA) and by the USDA Special Crop Research Initiative (SCRI) program (Project No. WPN03320).

Any opinions, findings, conclusions, or recommendations expressed in this publication are those of the author and do not necessarily reflect the view of the U.S. Department of Agriculture and Washington State University.

${ }^{1}$ Corresponding author.E-mail: manoj.karkee@wsu. edu.

Sweet cherry (Prunus avium L.) is one of the high-value fruit crops extensively planted in the U.S. Pacific Northwest region. Currently, fresh market sweet cherries are harvested manually by seasonal workforce. Because cherry fruit is small and scattered sparsely in tree canopies, manual harvesting is highly labor intensive and costly. As the availability of skilled labor is declining and the cost of labor is rising, researchers and growers have been seeking mechanical solutions for sweet cherry harvesting.

Vibration or shaking is one of the widely used methods for mechanical harvesting of tree fruit crops. To obtain the fundamental information for mechanical harvesting with vibration, researchers analyzed limb stiffness
(Erdoğan et al., 2003; Lenker and Hedden, 1968), and dynamic response of the tree under the vibration (Savary et al., 2010; Upadhyaya et al., 1981). Researchers also worked on identifying key factors for improving fruit removal rate and reducing harvest-induced damage (Halderson, 1966). Mechanical harvesting with vibration has been applied to different kinds of crops including citrus, pistachio nuts, and apricots (Erdoğan et al., 2003; Polat et al., 2006; Whitney, 1997).

Research on mechanical shaking method for harvesting sweet cherries dates back to the 1960s. Norton et al. (1962) used a hydraulic trunk shaker to harvest sweet cherries, and found that the harvesting methods removed $80-90 \%$ of the fruit. Markwardt et al. (1964) performed tests using a limb shaker in cherry harvesting, and found that the amount of energy transferred from the excitation point to the tree was dependent on branch diameter, branch length, and the point of shaker attachment. Peterson and Wolford (2001) developed a mechanical harvester using a rapid displacement actuator to apply impact force to the main scaffold to remove sweet cherries from trees. Despite the continuous research and development efforts over the past six decades, no mechanical harvester is commercially available for fresh market sweet cherry harvesting, largely because of excessive fruit damage induced during fruit detachment, falling through the tree canopy and impact on the catching surface (Peterson et al., 2003). Recently, Washington State University (WSU) researchers studied various aspects of the mechanical harvesting technology suitable for harvesting fresh market sweet cherries. These studies have resulted in optimal shaking frequencies and durations for designing an effective mechanical harvester with better fruit quality (Du et al., 2013; He et al., 2013; Zhou et al., 2013).

Fruit maturity is one of the key factors determining overall fruit quality. Generally, fruit maturity is not uniform either within individual trees or across an orchard. As a result, fruit harvested with a single-pass operation may include fruit with different maturity levels ranging from immature to over-mature (Horsfield et al., 1972). The lack of uniformity in fruit maturity levels with single-pass harvesting was identified as one of the most important factors affecting fruit quality (O'Brien et al., 1978). Research has been done to study the possibility of using a mechanical shaker to harvest fruit selectively by the fruit maturity level, and found that more mature fruit would have a lower retention force and could be released relatively easily (Claypool et al., 1968; Richardson et al., 1998). Sweet cherry cultivars exhibit natural variability in the detaching force, also referred to as pedicel-fruit retention force (PFRF), between pedicel and fruit ranging from 4.5 to $9.0 \mathrm{~N}$ (Smith and Whiting, 2010). Past studies show that shaking trees for a longer duration to detach immature fruit might induce more fruit damage because of the increased occurrence of fruit-to-fruit and/or fruit-to-tree impacts (Pellerin et al., 
1979). Selective harvesting to remove only mature fruit offers a potential to improve the uniformity of fruit maturity level and reduce harvest-induced fruit damage.

In conventional sweet cherry harvesting, generally, pickers go through trees only once to pick all fruit. Therefore, almost all previous mechanical harvesting research was based on single-pass harvesting. As discussed earlier, multipass harvesting methods could offer solutions to improve the quality of harvested fruit through improving uniformity in fruit maturity. In this study, we focused on the evaluation of both the functionalities and performances of a multipass mechanical harvesting system for sweet cherries, and are more focused on functionality. Specific objectives of this study were to 1) evaluate and compare the overall fruit removal efficiencies with multipass harvesting and single-pass harvesting methods; and 2) evaluate fruit maturity level and harvest-induced fruit damage rate with the multipass harvesting method and compare those achieved with single-pass harvesting method. To further validate the system, additional work should be carried out with more expanded experiments including wider variability in plant structures as well as different varieties and geographic locations.

\section{Materials and Methods}

Experimental harvesting system. Figure 1 illustrates the schematic of the experimental harvesting system, including a tree and the mechanical harvester. The mechanical shaker prototype (Fig. 2) used in this study was a research platform consisting of a hydraulically driven shaker, a hydraulic power unit, and an electro-hydraulic $(\mathrm{EH})$ control valve. In the shaker, a slide-crank mechanism was used to convert the rotational motion of the hydraulic motor (MGG20016, Parker Hannifin, Cleveland, $\mathrm{OH}$ ) to a linear oscillation of the shaker with a 36-mm stroke. A hydraulic power unit (HBHXL-05, Iron \& Oak Commercial Products, Streator, IL) was used to supply power to the shaker. An EH control valve (EFC12-1012, Brand Hydraulics, Omaha, NE) was used to adjust the shaking frequency by regulating the flow rate supplied to the motor. Actual shaking frequency was measured using a tachometer (HHT12, Omega, Stamford, CT). The shaker prototype also included a support frame consisting of a tool balancer, which is used to reduce the labor intensity of the operator during harvesting.

Experimental site. Harvesting tests were conducted at the WSU Roza Research Orchard (Prosser, WA) during 2012 harvest period from 9 July through 12 July 2012, which was the harvesting window for this orchard. The study was conducted on 'Skeena' sweet cherry trees nicely trained as Y-trellis architecture, which used five metal trellis wires on each side of the Y-shaped tree to train three to four primary branches at an elevation angle of $55^{\circ}$ to the ground. Trees were planted in a flat terrain with intrarow and interrow spacing of 1.5 and

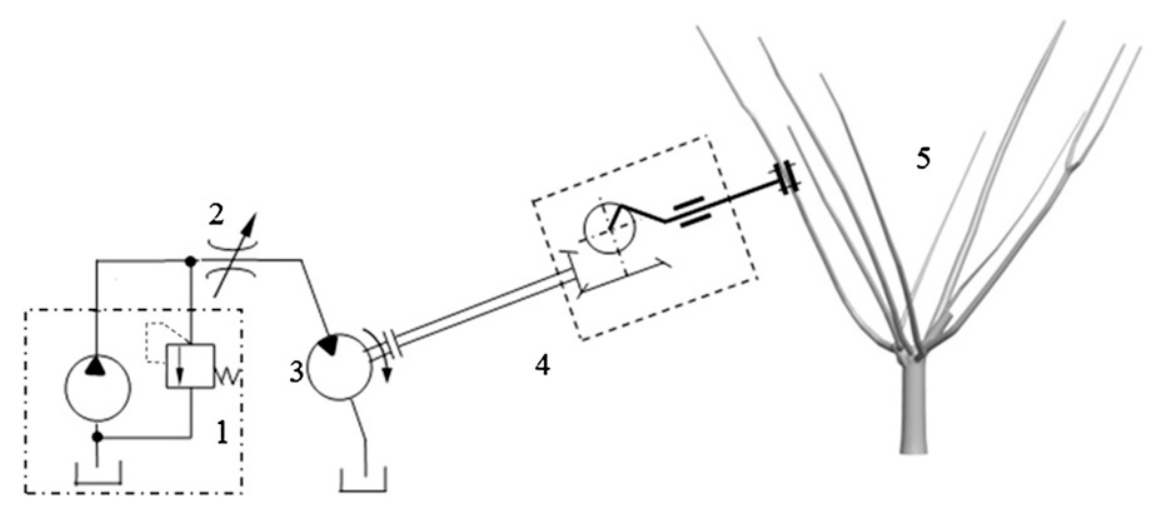

Fig. 1. Schematic of the experimental harvesting system. Label 1 is a hydraulic power unit (including a pump, a pressure relief valve, and a reservoir); 2 is an electro-hydraulic control valve; 3 is a hydraulic motor; 4 is a mechanical shaker; and 5 is a test tree.

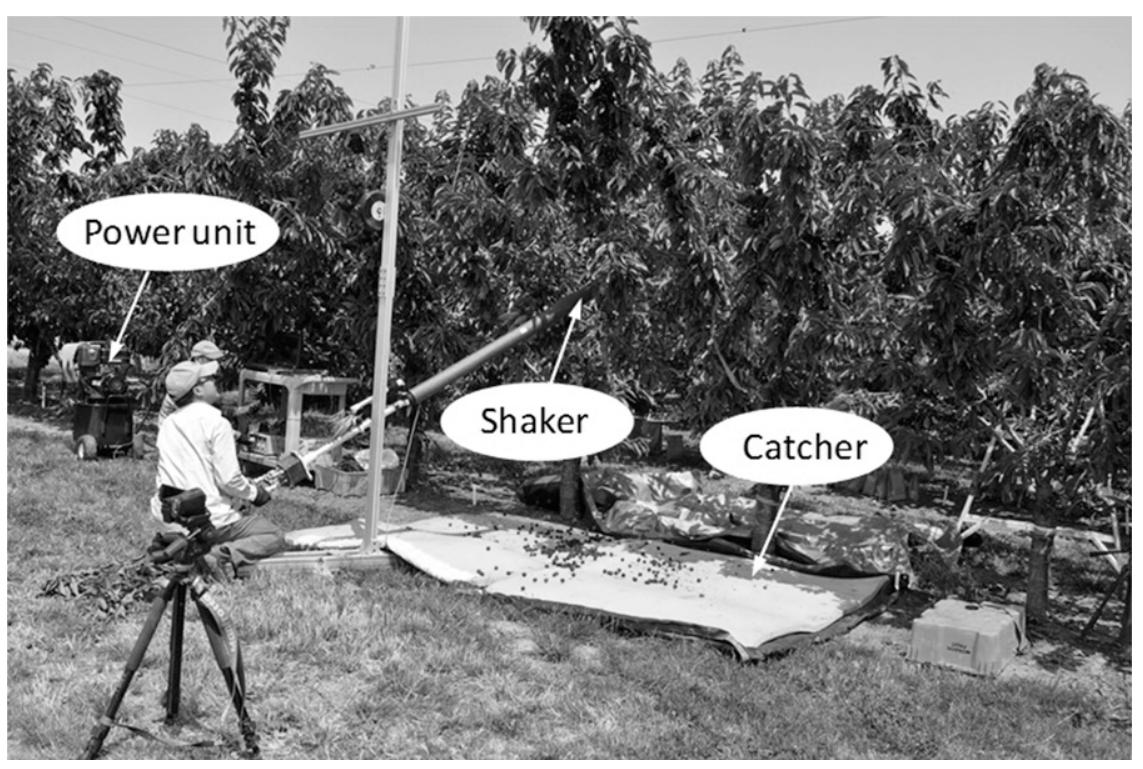

Fig. 2. The overview of test setup in sweet cherry orchard.

$4.0 \mathrm{~m}$, respectively. In the experiments, the selected limbs were located at the same orchard in the same row or neighboring row. The sizes of tested limbs varied from 2.5 to $3.8 \mathrm{~cm}$ in diameter with similar structure. During harvesting period, the weather was stable with calm air, and clear and sunny sky. The wind speed was from 3.3 to $3.9 \mathrm{mph}$ during the experiment days (AgWeatherNet, WSU). Tests were always conducted between 7:30 AM and 11:30 AM to avoid the effect of excessive heat in the afternoons on fruit removal condition and postremoval fruit quality.

Experimental design and field data collection. In this study, multipass harvesting was carried out by repeating harvesting operation on tree limbs for four consecutive days (one shaking event each day). Ten different limbs were randomly selected from both sides of tree canopies as the test set for the multipass harvesting. Past studies have shown that the $10 \mathrm{~s}$ overall vibration was a good shaking duration for sweet cherry harvesting to balance the fruit removal rate with fruit damage rate and energy consumption (He et al., 2013).
Therefore, each of the selected limbs was shaken for $2.5 \mathrm{~s}$ each day in the multipass harvesting. The harvested fruit were collected for fruit removal rate estimation and sampled immediately for fruit quality assessment. The same process was repeated each day for $4 \mathrm{~d}$ at about the same time of the day, resulting in a total shaking time of $10 \mathrm{~s}$ over $4 \mathrm{~d}$.

To provide baseline information for evaluating the performance of multipass harvesting, two single-pass harvesting operations at the first and last days of the multipass harvesting were conducted, namely, day 1 single-pass and day 4 single-pass harvesting. The first and last days presented two different harvesting conditions in terms of fruit maturity level, so these $2 \mathrm{~d}$ were selected for single-pass continuous shaking to capture this variability. In single-pass harvesting, 10 limbs were randomly selected for each of day 1 and day 4 harvestings. First 10 branches were shaken continuously for $10 \mathrm{~s}$ on the first day of multipass harvesting and the remaining 10 branches were shaken on the last day of multipass harvesting. In the tests, we assumed that the fruit in the four harvesting days goes through a linear progression on the 
maturity level, and we would capture the desired variability in fruit maturity level by performing experiments in the first and last days. With this assumption, the results from the middle of the $4 \mathrm{~d}$ will be similar to the average of the results from the first and last days.

To carry out harvesting, each tree limb was clamped tightly about at the middle with the adjustable hook of the shaker prototype and was shaken at a frequency of $14 \mathrm{~Hz}$. Past studies have shown that the desirable range of the shaking frequency for sweet cherry harvesting is from 12 to $18 \mathrm{~Hz}$ (Zhou et al., 2013). To ensure sufficient shaking energy while keeping the damage rate low, a frequency of $14 \mathrm{~Hz}$ was selected for this study.

Before attaching the shaker to the limbs, the engine was started to adjust the shaking frequency to desired level. The shaker was then stopped and the hydraulic pressure was held at that level. When we engaged the shaker to the limb and started shaking, the shaking frequency reached to the designed frequency very quickly. After the hook was attached at the selected shaking position of a limb, one operator held the shaker tightly during shaking operation to secure the vibration energy being transferred to the limbs. At the same time, another person turned on the switch and monitored the time with a stopwatch to turn the switch off at $2.5 \mathrm{~s}$ for multipass experiments or at $10 \mathrm{~s}$ for the single-pass experiments. It is noted that the manual control and hydraulic system both have some time lag and delay. However, we were careful to be consistent on manual timing and actuation of the shaking system so that the transient effect at the start and end of each shaking cycle remained consistent between shaking events. A sheet coated with half-inch soft sponge was laid under the tree on the ground to catch the harvested fruit and the sheet was big enough for catching almost all the mechanically harvested fruit. The fruit damage during catching process was ignored in this study. The fruit left on the limbs was manually picked after harvesting, and all the harvested fruit were weighed and sampled.

Before each test, 50 fruit samples were randomly selected from different locations of neighboring limbs on the test trees to measure the PFRF using a digital force gauge (DPS-11, Imada, Northbrook, IL). After each shaking, 50 fruit samples were randomly selected from the harvested fruit to evaluate color and assess damage. Fruit removal rate, fruit maturity levels, and the fruit damage rate of the different harvesting methods were compared with statistical analysis using analysis of variance in Tukey test at the 0.05 significance level.

Fruit maturity level. Skin color is an important indicator of maturity of sweet cherry fruit (Diaz-mula et al., 2009). In this study, the fruit maturity level of cherries was determined by comparing the skin color against a seven-level color chart (Cerise Color Chart, Center Technique Interprofessionnel des Fruit et Légumes, Paris, France). In this color chart, the scales from 1 of light red color to 7 of a dark mahogany color indicated the grade of maturity levels 1-7.
The color level 6 is regarded as mature for the 'Skeena' sweet cherries (Long et al., 2007). Hence, in this study, three different groups of maturity levels were used to illustrate the distribution of maturity levels of fruit harvested by the different harvesting methods: the under-mature group (distinguished by skin color level of 5 or less); the mature group (fruit with skin color level of 6); and the over-mature group (skin color level of 7). Fruit maturity distribution of the harvested fruit was investigated in this study to analyze the maturity uniformity of harvested fruit with the multipass and two single-pass harvesting methods. Fruit maturity distribution is defined as the percentage of harvested fruit at different maturity levels and expressed mathematically by Eq. [1]:

$$
\eta_{\mathrm{c}}=\frac{n_{\mathrm{c}}}{n} \times 100
$$

where $\eta_{\mathrm{c}}$ is the fruit maturity distribution at a certain maturity level $(\%) ; n_{\mathrm{c}}$ is the number of cherries harvested at a particular maturity level among the samples; and $n$ is the total number of sampled cherries being harvested.

Fruit removal rate. Fruit removal rate was defined as the percentage of the weight of mechanically harvested fruit against the weight of the total fruit growing on a test limb. To avoid harvesting fruit of neighboring limbs, all fruit on the neighboring limbs was manually picked before the tests. The total weight was calculated by adding the weight of the mechanically harvested fruit and the manually picked fruit after the harvest test. The fruit removal rate was determined using Eq. [2]:

$$
\eta_{\mathrm{r}}=\frac{M_{\mathrm{r}}}{M} \times 100
$$

where $\eta_{\mathrm{r}}$ is the fruit removal rate $(\%) ; M_{\mathrm{r}}$ is the weight of the mechanically harvested fruit $(\mathrm{kg})$; and $M$ is the weight of total fruit on the test limb $(\mathrm{kg})$.

Fruit damage rate. To assess the fruit damage rate using different harvesting methods, 50 fruit samples for each shaking were randomly selected from the harvested fruit within $1 \mathrm{~h}$ after each test. The collected fruit samples were stored immediately in a cold storage room $\left(\approx 0{ }^{\circ} \mathrm{C}\right.$ with $>95 \%$ relative humidity, forced air) for a week before quality assessment. All fruit samples with bruising, cutting, or pitting damage were considered damaged fruit, and the damage was from the shaking, catching, and also the natural culls. A total fruit damage rate was defined by Eq. [3]:

$$
\eta_{\mathrm{d}}=\frac{n_{\mathrm{d}}}{n} \times 100
$$

where $\eta_{\mathrm{d}}$ is the total fruit damage rate $(\%) ; n_{\mathrm{d}}$ is the number of damaged fruit in a sample; and $n$ is the total number of sampled fruit in a test.

The natural cull was caused by some natural sources, such as rain, wind, hail, and birds. In this study, four groups of fruit samples, weighing $0.77-0.95 \mathrm{~kg}$, were randomly picked by hand from the tested 'Skeena' block before harvesting, and used to estimate the natural cull rate, which was found to be $20.5 \%$. The damage induced by mechanical harvesting was calculated by subtracting the natural cull rate from total fruit damage rate using Eq. [4].

$$
\eta_{\mathrm{m}}=\eta_{\mathrm{d}}-\eta_{\mathrm{n}}
$$

where $\eta_{\mathrm{m}}$ is the mechanical harvest-induced damage rate; and $\eta_{n}$ is the natural cull rate of the harvested fruit.

\section{Results and Analysis}

Fruit maturity level. The mean fruit maturity levels of the three treatments are shown in Table 1, which shows that multipass harvesting resulted in the lowest percentage of under-mature fruit. In contrast, the day 1 single-pass harvesting obtained the highest percentage of under-mature fruit, followed by the day 4 single-pass harvesting. The statistics analysis revealed that multipass harvesting achieved a significantly lower percentage of under-mature fruit $(P$ value $<0.05)$ than that of the day 1 single-pass harvesting. Although the difference between multipass harvesting and day 4 single-pass harvesting was not statistically significant, the percentage of under-mature fruit of multipass harvesting was still noticeably lower on average. Obviously, as the harvesting day going, the fruits on the tree were getting more mature, that is one reason for more under-mature fruit at the day 1 single-pass harvesting. Another main reason could be there was less likelihood of detaching under-mature fruit with the short shaking duration applied each day with multipass harvesting. The results imply that multipass harvesting will effectively reduce the chance of harvesting under-mature fruit.

Table 1 also shows that the day 1 singlepass harvesting obtained the lowest percentage of over-mature fruit, followed by the multipass and the day 4 single-pass harvesting. The fruit were gaining maturity every day during the $4 \mathrm{~d}$ of field tests, such that the day 4 single-pass harvesting resulted in the highest percentage of fruit in the over-mature group. In multipass harvesting, the mature fruit were removed at each harvesting pass, reducing the likelihood of fruit becoming over-mature. Multipass harvesting removed significantly less over-mature fruit than the day 4 single-pass harvesting. Even though the day 1 single-pass harvesting achieved the lowest percentage of over-mature fruit, it harvested the highest percentage of under-mature fruit, which makes it a less desirable harvesting method.

In all tests, the majority of harvested fruit were in the mature level (color level 6), accounting for $77.6 \pm 8.0 \%, 80.8 \pm 4.0 \%$, and $69.2 \pm 18.9 \%$ for the day 1 single-pass harvesting, multipass harvesting, and the day 4 single-pass harvesting, respectively. Although the differences were not statistically significant, multipass tests on average harvested $3.2 \%$ and $11.6 \%$ more mature fruit respectively than the day 1 and the day 4 single-pass tests. Multipass harvesting had smaller percentage of under-mature and over-mature fruit, which meets the goal of harvesting fruit with uniform maturity. Short shaking durations were one of the reasons for 
this uniformity improvement in the multipass harvesting.

As described earlier, day 1 and day 4 single-pass harvestings were performed four days apart and the multipass harvesting was repeated each day over that duration. To understand the influence of maturity level on the fruit removal rate and fruit damage rate, an analysis on the difference in maturity level uniformity between the harvested fruit from day 1 single-pass and the first-pass of the multipass harvesting was performed (Table 1). Although the harvestings were conducted on the same day, the single-pass method achieved a higher percentage of under-mature fruit than the first pass of the multipass method. The result was attributed to the shorter shaking duration with the multipass harvesting that would deliver detaching force sufficiently to remove mature fruit but not the under-mature ones. On the other hand, $10 \mathrm{~s}$ of continuous shaking with single-pass harvesting delivered excessive energy detaching the immature fruit, which resulted in less uniform fruit maturity. In contrast, the difference in mature and over-mature fruit harvested by the two methods was insignificant. In general, multipass harvesting method achieved higher uniformity in maturity level of harvested fruit compared with the single-pass harvesting. This result shows a potential for improving fruit quality by harvesting sweet cherry in a few consecutive days with shorter shaking durations. There is no special pattern for the difference of fruit maturity levels among four passes in multipass harvesting. Furthermore, the difference between the day 4 single-pass harvesting and the fourth pass of multipass is insignificant in all three maturity levels (Table 1).

Fruit quality and fruit removal rate. As the average fruit maturity level increased from $5.8 \pm 0.2$ to $6.1 \pm 0.1$ between day 1 and day 4, the corresponding average PFRF decreased from $6.0 \pm 1.4$ to $5.1 \pm 1.3 \mathrm{~N}$ (Table 2). The multipass harvesting selectively removed mature fruit each day over the 4-d period. It was not possible to collect consistent samples for PFRF measurement as the number of fruit remaining in these trees declined. Therefore, there was no exact PFRF

Table 1. Maturity-level distribution of harvested fruit with different harvesting methods.

\begin{tabular}{lcccc}
\hline \multirow{2}{*}{ Harvesting treatments } & \multicolumn{2}{c}{ Maturity-level distribution of harvested fruit (\%) } \\
\cline { 3 - 5 } \multicolumn{2}{l}{$\begin{array}{l}\text { Day 1 single-pass } \\
\text { Multipass }\end{array}$} & Under-mature & Mature & Over-mature \\
\cline { 2 - 4 } & Day 1 & $19.4 \pm 10.0 \mathrm{a}$ & $77.6 \pm 8.0 \mathrm{~d}$ & $3.2 \pm 9.9 \mathrm{e}$ \\
& Day 2 & $4.6 \pm 6.3 \mathrm{~b}$ & $83.7 \pm 7.7 \mathrm{~d}$ & $4.7 \pm 4.5 \mathrm{e}$ \\
& Day 3 & $12.2 \pm 9.3 \mathrm{~b}$ & $81.1 \pm 9.8 \mathrm{~d}$ & $14.4 \pm 9.1 \mathrm{fg}$ \\
& Day 4 & $12.0 \pm 10.0 \mathrm{~b}$ & $80.6 \pm 11.4 \mathrm{~d}$ & $7.2 \pm 5.4 \mathrm{ef}$ \\
& Overall & $9.2 \pm 4.8 \mathrm{~b}$ & $80.8 \pm 4.0 \mathrm{~d}$ & $15.1 \pm 12.8 \mathrm{fg}$ \\
Day 4 single-pass & & $11.2 \pm 15.6 \mathrm{ab}$ & $69.2 \pm 18.9 \mathrm{~d}$ & $9.9 \pm 4.4 \mathrm{f}$ \\
\hline
\end{tabular}

Test results of maturity level, fruit damage rate, and removal efficiency of each individual pass in multipass harvesting are shown in Table 3 . The maturity level of the harvested fruit among $4 \mathrm{~d}$ in the multipass harvesting varied from $5.9 \pm 0.1$ to $6.1 \pm 0.2$, with no significant differences among four passes. The average fruit removal rate was $21.3 \% \pm 15.0 \%, 29.6 \% \pm 13.2 \%, 22.6 \% \pm$ $8.9 \%$, and $9.9 \% \pm 5.8 \%$ for each successive day respectively. The fruit removal rate from the last pass was found to be significantly lower than the other passes. The visual observation over those field test suggested that the difference was most likely attributed to limited number of fruit remaining on the trees after three sequential passes of harvesting.

One important fact observed from this multipass test was that the overall fruit damage rate increased over the successive harvesting passes from day 1 to day 4 (Table 3). The overall fruit damage rates with the last two passes were significantly higher than that from the first two passes. One of the most likely reasons for such an increase in the damage rate was the fact that fruit being left in the tree after the first two passes of shaking had an increased chances of being subjected to both fruit-to-fruit and fruit-tobranch impacts.

Fruit damage source. Fruit damage due to mechanical harvesting is related to many factors, including fruit maturity. The fruit damage rate in different fruit maturity level in three test sets was shown in Table 4. The damage rate of fruit with the under-mature level was the highest at the day 1 single-pass harvesting, which is because there were more fruit in the maturity level of 3 or 4 compared with fruit with other harvesting methods. Under-mature fruit needs a longer time to be removed, which causes more fruit-to-fruit or fruit-to-branch impacts resulting in a high fruit damage rate. Considering the relationships of PFRF and removal efficiencies related to fruit maturity levels discussed earlier, bigger PFRF, or lower fruit maturity level limited the fruit removal rate and caused more fruit damage. For example, the fruit removal rate in the day 1 single-pass harvesting was only $48.0 \% \pm 16.1 \%$ (Table 2 ), and about half of the harvested fruit with maturity level of 5 and less was damaged in the day 1 single-pass harvesting and multipass harvesting (Table 4).

The results also showed that the damage rates of multipass harvesting continuously and significantly decreased as fruit maturity level increased from under-mature to overmature (Table 4). It is also found that there was significant difference in the fruit damage

Table 2. Fruit removal rate, fruit damage rate, and fruit maturity level with multipass and single-pass harvesting methods.

\begin{tabular}{|c|c|c|c|c|c|}
\hline Harvesting method & Pedicel-fruit retention force $(\mathrm{N})$ & Maturity level & Removal rate $(\%)$ & Overall damage rate $(\%)$ & Harvest-induced damage rate $(\%)$ \\
\hline Day 1 single-pass & $6.0 \pm 1.4$ & $5.8 \pm 0.2 \mathrm{a}^{z}$ & $48.0 \pm 16.1 \mathrm{a}$ & $40.5 \pm 9.9$ & $20.1 \pm 9.9 \mathrm{a}$ \\
\hline Day 4 single-pass & $5.1 \pm 1.3$ & $6.1 \pm 0.1 \mathrm{~b}$ & $66.7 \pm 16.2 b$ & $32.2 \pm 6.0$ & $11.8 \pm 6.0 \mathrm{~b}$ \\
\hline Multipass & - & $6.0 \pm 0.1 \mathrm{~b}$ & $83.4 \pm 10.3 \mathrm{c}$ & $25.4 \pm 4.4$ & $5.0 \pm 4.4 \mathrm{c}$ \\
\hline
\end{tabular}

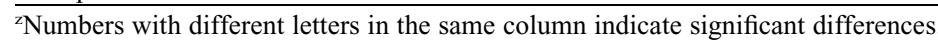


Table 3. Fruit removal rate and fruit damage rate in four passes of multipass harvesting.

\begin{tabular}{lccc}
\hline Pass sequence & Maturity level & Removal rate $(\%)$ & Damage rate $(\%)$ \\
\hline Day 1 & $5.9 \pm 0.1 \mathrm{a}$ & $21.3 \pm 15.0 \mathrm{a}$ & $20.0 \pm 6.6 \mathrm{a}$ \\
Day 2 & $6.1 \pm 0.1 \mathrm{a}$ & $29.6 \pm 13.2 \mathrm{a}$ & $21.2 \pm 5.2 \mathrm{a}$ \\
Day 3 & $5.9 \pm 0.1 \mathrm{a}$ & $22.6 \pm 8.9 \mathrm{a}$ & $31.0 \pm 5.3 \mathrm{~b}$ \\
Day 4 & $6.1 \pm 0.2 \mathrm{a}$ & $9.5 \pm 5.8 \mathrm{~b}$ & $33.4 \pm 16.9 \mathrm{~b}$ \\
\hline
\end{tabular}

Table 4. Fruit damage rate related to each maturity level in different harvesting methods.

\begin{tabular}{llcc}
\hline & \multicolumn{2}{c}{ Fruit damage rate in different maturity levels (\%) } \\
\cline { 2 - 4 } Harvesting treatments & Under-mature & Mature & Over-mature \\
\hline Day 1 single-pass & $63.9 \pm 21.7 \mathrm{a}$ & $37.1 \pm 6.8 \mathrm{~b}$ & None \\
Multipass & $46.8 \pm 14.2 \mathrm{ab}$ & $23.9 \pm 4.2 \mathrm{c}$ & $11.7 \pm 11.0 \mathrm{~d}$ \\
Day 4 single-pass & $36.5 \pm 30.5 \mathrm{~b}$ & $33.8 \pm 7.1 \mathrm{~b}$ & $28.8 \pm 17.2 \mathrm{bc}$ \\
\hline
\end{tabular}

rates of day 1 single-pass and multipass harvesting (Table 4). The likelihood of fruitto-fruit and/or fruit-to-branch impact was reduced in the detaching of mature fruit because it was easier to remove mature fruit than under-mature fruit, leading to lower harvestinduced fruit damage. The fruit damage rate in the mature level was significantly lower in the multipass harvesting than the two single-pass harvestings, which also could be attributed to the shorter shaking duration causing less fruitto-fruit and/or fruit-to-branch impact.

In addition, Table 4 also shows that reduced fruit damage rates were found in the over-mature group with all harvesting methods. One possible reason for this phenomenon was that the fruit in this maturity level could be removed within a very short time reducing chances of fruit-to-fruit and fruit-to-branch impact. In addition, it was noted the majority of the over-mature fruit was close to color grade 7 but not quite there, and the fruit was still in good condition. However, this fruit is more likely to be damaged during transportation and storage.

Overall, the results showed that multipass harvesting with a short shaking duration over a few days could obtain the highest fruit removal rate with the lowest fruit damage rate, and improved uniformity in maturity level. The multipass harvesting approach shows promise for a more efficient and effective mechanical harvesting solution for fresh market sweet cherries. The paper is more on functionality scale test, and the field-scale test will be conducted based on the developed multipass harvesting methodology in our future research. Furthermore, multipass harvesting methods may reduce the overall work efficiency. An extensive economic analysis is essential to establish overall viability of multipass harvesting methods for adoption by growers, which was beyond the scope of this study.

\section{Conclusions}

This study investigated the performance of a novel harvesting method, multipass mechanical harvesting, for effectively harvesting fresh market sweet cherries. The three fundamental criteria used to measure the performance of the harvesting methods were fruit removal rate, fruit damage rate, and fruit maturity level. To obtain the necessary information for supporting an objective assessment, a set of 4-d multipass harvestings, companioning with two one-pass harvests, were conducted in the 'Skeena' sweet cherry orchard. By comparing the performance of multipass harvesting with single-pass harvesting, the following specific conclusions from this work were summarized:

1. Multipass harvesting of sweet cherries increased the chances of harvesting fruit at the right maturity level. Compared with the day 1 single-pass harvesting, the percentage of harvested fruit in the fruit maturity level of 5 or less was significantly lower in the multipass harvesting. Similarly, multipass harvesting achieved a noticeably lower percentage of fruit in the under-mature group compared with the day 4 single-pass harvesting.

2. The fruit removal rate with multipass harvesting was $83.4 \%$, which was significantly higher than those with day 1 single-pass harvesting and the day 4 single-pass harvesting.

3. Multipass harvesting achieved the lowest mechanically harvest-induced fruit damage rate of $5.0 \%$, compared with $20.1 \%$ and $11.8 \%$ with the day 1 singlepass and the day 4 single-pass harvesting. Low fruit maturity level was one of the potential fruit damage sources for the harvested fruit. Long shaking duration was another potential damage source due to the increased chance of fruit-to-fruit and fruit-to-branch impact.

In summary, the results indicated that the multipass harvesting system could be suggested as a good harvesting method with the potential for improving fruit removal rate and fruit quality.

\section{Literature Cited}

Claypool, L.L., R.B. Fridley, P.A. Adrian, and P.F. Lasker. 1968. Mechanisation of apricot harvesting. Research progress report. Uni. California Mimeograph, CA.

Diaz-Mula, H.M., S. Castillo, D. MartinezRomero, D. Valero, P.J. Zapata, F. Guillen, and M. Serrano. 2009. Sensory, nutritive and functional properties of sweet cherry as affected by cultivar and ripening stage. Food Sci. Technol. Intl. 15(6):535-543.
Du, X., D. Chen, Q. Zhang, P. Scharf, and M. Whiting. 2013. Response of UFO (Upright Fruiting Offshoots) on cherry trees to mechanical harvest by dynamic vibratory excitation. Trans. ASABE 56(2):345-354.

Erdoğan, D., M. Güner, E. Dursun, and İ. Gezer. 2003. Mechanical harvesting of apricots. Biosystems Eng. 85(1):19-28.

Halderson, J.L. 1966. Fundamental factors in mechanical cherry harvesting. Trans. ASAE 9(5):681-684.

He, L., J. Zhou, X. Du, D. Chen, Q. Zhang, and M. Karkee. 2013. Energy efficacy analysis of a mechanical shaker in sweet cherry harvesting. Biosystems Eng. 116(4):309-315.

Horsfield, B.C., R.B. Fridley, and L.L. Claypool. 1972. Optimizing mechanical harvesting procedures for apricots of nonuniform maturity. Trans. ASAE 15(5):878-882.

Long, L.E., M. Whiting, and R. Nuñez'Elisea. 2007. Sweet cherry cultivars for the fresh market. 5 Jan. 2013. <http://extension.oregonstate. $\mathrm{edu} />$.

Lenker, D.H. and S.L. Hedden. 1968. Limb properties of citrus as criteria for tree-shaker design. Trans. ASAE 11(1):129-131.

Markwardt, E.D., R.W. Guest, J.C. Cain, and R.L. Labelle. 1964. Mechanical cherry harvesting. Trans. ASAE 7(1):70-74, 82.

Norton, R.A., L.L. Claypool, S.J. Leonard, P.A. Adrian, R.B. Fridley, and F.M. Charles. 1962. Mechanical harvesting of sweet cherries: 1961 tests show promise and problems. Calif. Agr. 16(5):8-10.

O'Brien, M., R.B. Fridley, and L.L. Claypool. 1978. Food losses in harvest and handling systems for fruit and vegetables. Trans. ASAE 21(2):386-390.

Peterson, D.L. and S.D. Wolford. 2001. Mechanical harvester for fresh market quality stemless sweet cherries. Trans. ASAE 44(3):481-485.

Peterson, D.L., M.D. Whiting, and S.D. Wolford. 2003. Fresh-market quality tree fruit harvester: Part I: Sweet cherry. Appl. Eng. Agr. 19 (5):539-543.

Pellerin, R.A., W.F. Millier, A.N. Lakso, G.E. Rehkugler, and J.A. Throop. 1979. Apple harvesting with an inertial vs. impulse trunk shaker on open-center and central-leader trees: Part II. Trans. ASAE 22(5):983-988.

Polat, R., I. Gezer, M. Guner, E. Dursun, D. Erdogan, and H.C. Bilim. 2006. Mechanical harvesting of pistachio nuts. J. Food Eng. 79 (4):1131-1135

Richardson, D.G., R.L. Stebbins, D. Kirk, D. Booster, L. Jensen, and R. Cain. 1998. Brining cherry mechanical harvest: Fruit maturity and machine factors involved in stem retention and bruising. Acta Hort. 468:741-746.

Savary, S.K.J.U., R. Ehsani, J.K. Schueller, and B.P. Rajaraman. 2010. Simulation study of citrus tree canopy motion during harvesting using a canopy shaker. Trans. ASABE 53(5): 1373-1381.

Smith, E. and M. Whiting. 2010. Effect of ethephon on sweet cherry pedical-fruit retention force and quality is cultivar dependent. Plant Growth Regulat. 60(3):213-223.

Upadhyaya, S.K., J.R. Cooke, and R.H. Rand. 1981. Dynamics of fruit tree trunk impact. Trans. ASAE 24(4):846-855.

Whitney, J.D. 1977. Design and performance of an air shaker for citrus fruit removal. Trans. ASAE 20(1):52-56.

Zhou, J., L. He, X. Du, D. Chen, Q. Zhang, and M. Karkee. 2013. Evaluation of the influence of shaking frequency and duration in mechanical harvest of sweet cherries. Appl. Eng. Agr. 29 (5):607-612. 